\title{
Adsorption of Dibenzothiophene in Gasoline by Si-MCM-41/ Sodium Alginate Porous Hybrid Membrane
}

\author{
QIAO JING LIN ${ }^{1}$, XUE SUN ${ }^{1}$, JIAN HUA CHEN ${ }^{1,2^{*}}$, JING MEI WANG ${ }^{1}$, WEI WEI LIN ${ }^{1}$, \\ LI JUN FANG ${ }^{1}$ \\ ${ }^{1}$ College of Chemistry, Chemical Engineering and Environment, Minnan Normal University, Zhangzhou 363000, China \\ ${ }^{2}$ Fujian Province University Key Laboratory of Modern Analytical Science and Separation Technology, Minnan Normal \\ University, Zhangzhou 363000, China
}

\begin{abstract}
In this paper, the novel Si-MCM-41/SA porous hybrid membrane was prepared by incorporating inorganic mesoporous material Si-MCM-41 into sodium alginate (SA) matrix, then crosslinking with 5\% glutaraldehyde and $1.0 \mathrm{~mol} / \mathrm{L}$ hydrochloric acid. Using scanning electron microscope (SEM), X-ray diffraction (XRD), thermogravimetric analysis (TGA) and atomic force microscope (AFM), the prepared Si-MCM-41 sample and Si-MCM-41/SA porous hybrid membrane were characterized. The adsorption kinetics of the dibenzothiophene (DBT) by the Si-MCM-41/SA porous hybrid membrane was explored. Meanwhile, the effects of Si-MCM-41 content, porogen addition amount, DBT concentration, solution temperature, toluene concentration and other factors on the adsorption property of the Si-MCM-41/SA porous hybrid membrane were studied. In addition, the selectivity and reusability of the Si-MCM-41/SA porous hybrid membrane were also explored. The results show that the Si-MCM-41/SA porous hybrid membrane has excellent adsorption capacity for $D B T$, reaching $350.74 \mathrm{mg} / \mathrm{g}$, which is a great improvement over the pure SA membrane. Moreover, among three sulfides of thiophene, 3-methylthiophene and DBT, the Si-MCM-41/SA porous hybrid membrane has the highest adsorption selectivity for DBT. The Si-MCM-41/SA porous hybrid membrane can be reused at least 5 times. Therefore, it can be known that the Si-MCM-41/SA porous hybrid membrane is an ideal adsorption material with practical application prospects.
\end{abstract}

Keywords: Si-MCM-41, adsorption, porous hybrid membrane, dibenzothiophene

\section{Introduction}

With the gradual deterioration of the world's environmental and the need for social sustainability development, the sulfur content of gasoline has attracted the attention of researchers and enterprises around the world. The removal of sulfur compounds, such as hydrogen sulfide, thiols, alkyl sulfide, from gasoline can be achieved by simple catalytic hydrogenation [1,2]. However, thiophene and its derivatives are difficult to remove by this method. For this reason, deep desulfurization is facing severe challenges. The industry urgently needs to develop a new desulfurization method or high efficiency adsorbent to carry out deep desulfurization [3].

The traditional catalytic hydrogenation method has higher requirements for the safety of production equipment due to the use of hydrogen in the production process. The mechanism of DBT through ordinary catalytic hydrodesulfurization (HDS) is shown in the Figure 1 [4,5]. HDS is a nonselective hydrogenation process that requires high temperature and high pressure. The process also requires substantial quantities of $\mathrm{H} 2$, which is expensive [6-8]. Therefore, new catalysts or deep desulfurization method is required. Adsorptive desulfurization technology has attracted many researchers' attention because of its mild conditions, low operation cost and simple process. The key point of adsorption desulfurization (ADS) technology is the preparation of high efficiency adsorbents. The preparation of an efficient, cheap, simple and reusable adsorbent has become the focus and difficulty in the research of ADS industry [9]. Among them, the most commonly used adsorbents are carbon materials, molecular sieve, metal-organic frameworks materials [10-13]. With the development of membrane separation

\footnotetext{
*email:jhchen73@126.com
} 
technology, a new separation method combining membrane separation technology with adsorption separation has attracted wide attention in the industry. The emphasis of membrane adsorption separation is the selection of polymer membrane materials, inorganic hybrid materials and their blending methods [14-16].

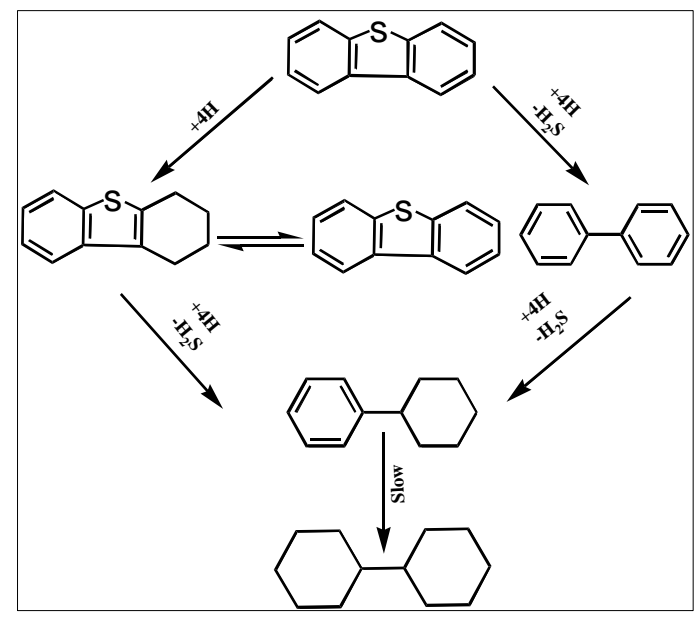

Figure 1. Catalytic hydrodesulfurization process

In the synthesis of mesoporous material-41(Si) (Si-MCM-41) [2,17-20], cetyl ammonium bromide is needed as the template, and the removal of the template in the post-treatment process leads to its regular pore structure. It has large pore size $(1.5-10 \mathrm{~nm})$, high specific surface area (over $700 \mathrm{~m}^{2} / \mathrm{g}$ ) and high adsorption capacity, which has the properties required for the adsorption material [21]. Moreover, the removal of the template exposed some active sites, which provided binding sites for the sulfide and improved the removal efficiency of the sulfide [22]. Its pore size is similar to that of DBT, and it can be stabilized in water and in simulated oil (n-heptane-DBT). Sodium alginate (SA) is a hydrophilic polymer material with outstanding membrane forming properties, its active functional groups such as hydroxyl and carbonyl make it have high adsorption efficiency [23]. Therefore, in this study, using Si-MCM-41 and SA, the Si-MCM-41/SA porous hybrid membranes were prepared, then cross-linking Si-MCM41/SA porous hybrid membranes in $1.0 \mathrm{~mol} / \mathrm{L} \mathrm{HCl}$ and $5 \mathrm{w} \%$ glutaraldehyde solutions. The adsorption of DBT on Si-MCM-41/SA porous hybrid membranes was investigated by optimizing the preparation and experimental conditions.

\section{Materials and methods}

\subsection{Chemicals and materials}

Sodium alginate (CP), n-heptane (CP), ethyl alcohol absolute (AR), hydrochloric acid (AR), glutaric dialdehyde (AR), ammonium hydroxide $(25 \%, \mathrm{AR})$ and tetraethyl orthosilicate (TEOS, AR) were supplied by Xilong Chemical Co. Ltd. Dibenzothiophene (DBT, AR), thiophene (AR) and 3-methylthiophene (AR) were from Shanghai Aladdin Reagent Co. Ltd. Cetyltrimethylammonium bromide (CTAB, AR) and polyvinyl pyrrolidone k-30 (PVP, AR) were purchased from Sinopharma Chemical Reagent Co.Ltd.

\subsection{Detection of DBT in samples}

The concentration of DBT in n-heptane/DBT mixtures was tested by gas chromatography using temperature programmed method. The injector temperature was $250^{\circ} \mathrm{C}$, first-order temperature was $90^{\circ} \mathrm{C}$, the second-order temperature was $210^{\circ} \mathrm{C}$, hydrogen flame ionization detector (FID) temperature was $250^{\circ} \mathrm{C}$. The chromatographic column was $10 \%$ SE-30. The concentration of thiophene, 1-benzothiophene and 3-methylthiophene were determined under the condition of nitrogen $4.5 \mathrm{~mL} / \mathrm{min}$, hydrogen 5 $\mathrm{mL} / \mathrm{min}$, air $5 \mathrm{~mL} / \mathrm{min}$ and tail blowing $4.4 \mathrm{~mL} / \mathrm{min}$. 


\subsection{Synthesis of $\mathrm{Si}-\mathrm{MCM}-41$}

Mesoporous material of Si-MCM-41 was obtained by using following procedure: CTAB $(0.5 \mathrm{~g})$ was dissolved in $96 \mathrm{~mL}$ deionized water to obtain a clear solution. To the solution, $34 \mathrm{~mL}$ ethanol and 10 $\mathrm{mL} 25 \%$ ammonia water were added and stirred for $5 \mathrm{~min}$. Then, $2 \mathrm{~mL}$ of TEOS was added and stirred for $3 \mathrm{~h}$ at room temperature. The obtained precipitate was washed with deionized water and dried in an oven at $80^{\circ} \mathrm{C}$ for $8 \mathrm{~h}$. Finally, it was calcined at $540^{\circ} \mathrm{C}$ for $9 \mathrm{~h}$.

\subsection{Preparation of Si-MCM-41/SA porous hybrid membrane}

Casting solution was obtained by dissolve certain amount of sodium alginate, Si-MCM-41 and PVP in deionized water. Take a certain amount of casting solution and pour it on the glass plate to form a liquid membrane, and dried at $60^{\circ} \mathrm{C}$. Then the membrane was crosslinked using $5 \%$ glutaraldehyde and $1.0 \mathrm{~mol} / \mathrm{L}$ hydrochloric acid mixture for $5 \mathrm{~h}$. Finally, the pore forming agent in the membrane was washed away, dried and ready for use.

\subsection{Characterization of Si-MCM-41 and membrane}

The surface morphology of Si-MCM-41 and Si-MCM-41/SA porous hybrid membranes was observed by scanning electron microscope (SEM, JSM-6010LA, Japan). The thermal stability of SiMCM-41 and Si-MCM-41/SA porous hybrid membrane was investigated by thermogravimetric analysis (TGA 209 F1, Netzsch). The crystal structure and phase composition of the sample were analyzed by X-ray diffraction (XRD, D/MAXTTRIII), and the surface structure of SA-based membrane was studied by atomic force microscopy (AFM, CSPM5500).

\subsection{Adsorption experiment}

\subsubsection{Study on the adsorption kinetics of Si-MCM-41/SA porous hybrid membrane for DBT}

Add $0.02 \mathrm{~g}$ of Si-MCM-41/SA porous hybrid membrane (8 wt\% Si-MCM-41, $80 \mathrm{wt} \% \mathrm{PVP}$ ) to 100 $\mathrm{mL}, 300 \mathrm{mg} / \mathrm{L}$ DBT solution, then it was place on a constant temperature gas bath oscillator $\left(30^{\circ} \mathrm{C}\right)$. Finally, samples were collected at set intervals for detection.

\subsubsection{Effect of DBT concentration on adsorption}

A series of DBT solutions with concentrations of 100, 200, 300, 400 and $500 \mathrm{mg} / \mathrm{L}$ were prepared using n-heptane as solvent. Add $0.02 \mathrm{~g}$ of Si-MCM-41/SA porous hybrid membrane to $50 \mathrm{~mL}$ of each solution, and shake at $30^{\circ} \mathrm{C}$ for $24 \mathrm{~h}$. Then the concentration of each solution after the adsorption was measured and the adsorption capacity of the Si-MCM-41/SA porous hybrid membrane was calculated.

\subsubsection{Effect of temperature on adsorption}

Take five parts of $50 \mathrm{~mL} 300 \mathrm{mg} / \mathrm{L}$ DBT solution, then add $0.02 \mathrm{~g} \mathrm{Si-MCM-41/SA} \mathrm{porous} \mathrm{hybrid}$ membrane to each part, and place them in a water bath for adsorption at $30,35,40,45,50^{\circ} \mathrm{C}$ for $24 \mathrm{~h}$, respectively. Then the concentration of each solution after the adsorption was measured and the adsorption capacity of the Si-MCM-41/SA porous hybrid membrane was calculated.

\subsubsection{Effect of the concentration of toluene on adsorption}

The n-heptane solution with DBT concentration of $300 \mathrm{mg} / \mathrm{L}$ and toluene concentration of 100, 200, 300,400 and $500 \mathrm{mg} / \mathrm{L}$ were prepared, respectively. Add $0.02 \mathrm{~g}$ of Si-MCM-41/SA porous hybrid membrane to $50 \mathrm{~mL}$ of each concentration of n-heptane solution, and then keep them at $30^{\circ} \mathrm{C}$ and shaking for $24 \mathrm{~h}$. Then the concentration of each solution after the adsorption was measured and the adsorption capacity of the Si-MCM-41/SA porous hybrid membrane was calculated.

\subsubsection{Selectivity study}

The n-heptane solution with thiophene, 3-methylthiophene, and DBT concentration of 500, 600, 700, 800 , and $900 \mathrm{mg} / \mathrm{L}$ were prepared, respectively. Add $0.02 \mathrm{~g}$ of Si-MCM-41/SA porous hybrid membrane 
to $25 \mathrm{~mL}$ of each concentration of n-heptane solution, and then keep them at $30^{\circ} \mathrm{C}$ and shaking for $24 \mathrm{~h}$. Then the concentration of each solution after the adsorption was measured and the adsorption capacity of the Si-MCM-41/SA porous hybrid membrane was calculated.

\subsubsection{Reusability study}

Add $0.02 \mathrm{~g}$ of Si-MCM-41/SA porous hybrid membrane to $25 \mathrm{~mL}$-heptane solution with DBT concentration of $300 \mathrm{mg} / \mathrm{L}$. Put it in a constant temperature shaker at $30^{\circ} \mathrm{C}$ for $24 \mathrm{~h}$, then measuring the concentration of the n-heptane solution after adsorption to determine the adsorption capacity of SiMCM-41/SA porous hybrid membrane, and place the adsorbed Si-MCM-41/SA porous hybrid membrane in a Soxhlet extractor for $12 \mathrm{~h}$. Finally, the Si-MCM-41/SA porous hybrid membrane was placed in an oven at $60^{\circ} \mathrm{C}$ for drying. Repeat the above operation 5 times.

\section{Results and discussions}

\subsection{Characterization of the prepared adsorbent}

\subsubsection{Scanning electron microscope (SEM) analysis}

Figure 2 shows the SEM images of Si-MCM-41, SA pure membrane and Si-MCM-41/SA porous hybrid membrane. It can be seen from Figure $2 \mathrm{a}$ that the size of the prepared Si-MCM-41 is about 250 $\mathrm{nm}$. It is helpful to obtain uniform Si-MCM-41/SA porous hybrid membrane. From the Figure $2 b$ and $2 c$, we can see that the surface of the pure SA membrane is uniform, however, the surface of Si-MCM41/SA porous hybrid membrane is rougher. It also showed that there are a large number of holes in the Si-MCM-41/SA porous hybrid membrane, and Si-MCM-41 is evenly dispersed. A large amount of SiMCM-41 is loaded on the Si-MCM-41/SA porous hybrid membrane, and it has more pores with large diameters, which is conducive to the transfer of thiophene sulfides to the interior of the Si-MCM-41/SA porous hybrid membrane for adsorption [24, 25]. As the amount of Si-MCM-41 in the Si-MCM-41/SA porous hybrid membrane increases, seen from the Figure $2 \mathrm{~d}$, the agglomeration of Si-MCM-41 in the Si-MCM-41/SA porous hybrid membrane results in the decrease of the specific surface area, which is not conductive to adsorption.

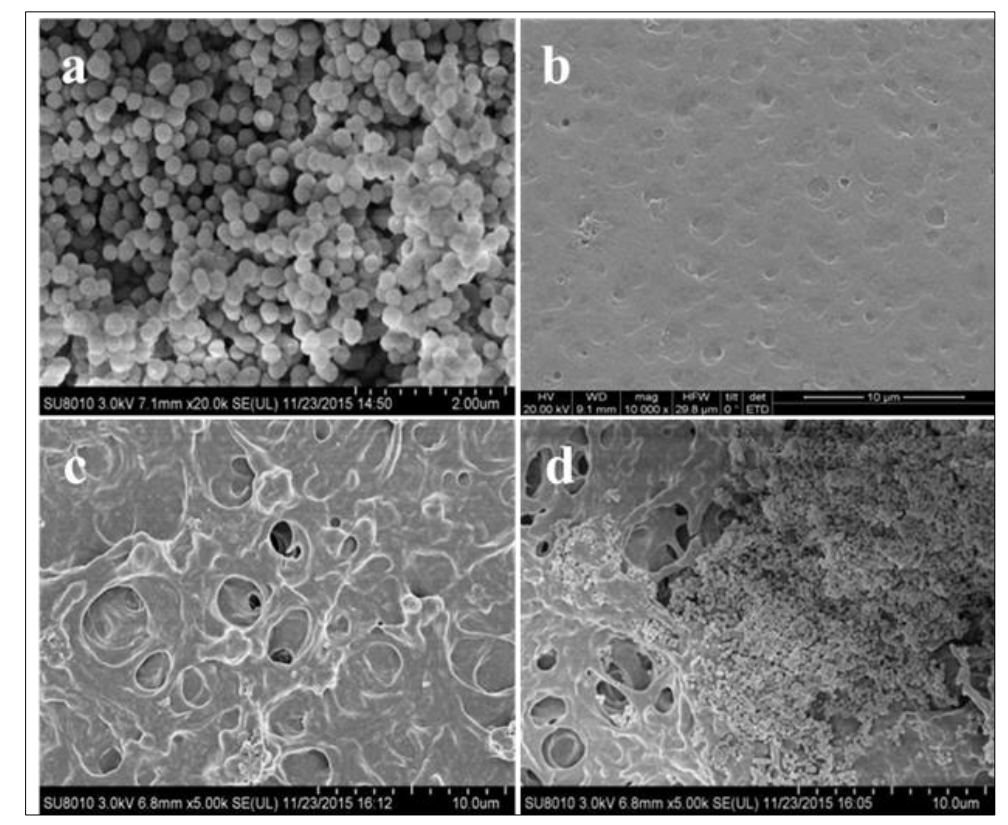

Figure 2. SEM images of a) Si-MCM-41; b) Sodium alginate pure membrane; c) 8 wt \% Si-MCM-41 hybrid membrane;

d) $10 \mathrm{wt} \% \mathrm{Si}-\mathrm{MCM}-41$ hybrid membrane 


\subsubsection{Thermogravimetric Analysis (TGA)}

The TGA is used to evaluate the stability of adsorbents in the temperature range of 0 to $800^{\circ} \mathrm{C}$ under $\mathrm{N}_{2}$ atmosphere. TG curves of Si-MCM-41 and Si-MCM-41/SA hybrid membrane is shown in Figure 3. As can be seen from Figure 3, the weight loss of Si-MCM- 41 is about $3 \%$ at $800^{\circ} \mathrm{C}$, indicating Si-MCM41 has good thermal stability. The TGA curve of Si-MCM-41/SA porous hybrid membrane shows that the weight loss of it is mainly due to the evaporation of water in porous hybrid membrane when the temperature is lower than $200^{\circ} \mathrm{C}$. When the temperature is higher than $200^{\circ} \mathrm{C}$, the main reason is the decomposition of sodium alginate. Because the experimental temperature is lower than $100^{\circ} \mathrm{C}$, the thermal stability of the porous hybrid membrane can meet the requirements of ADS.

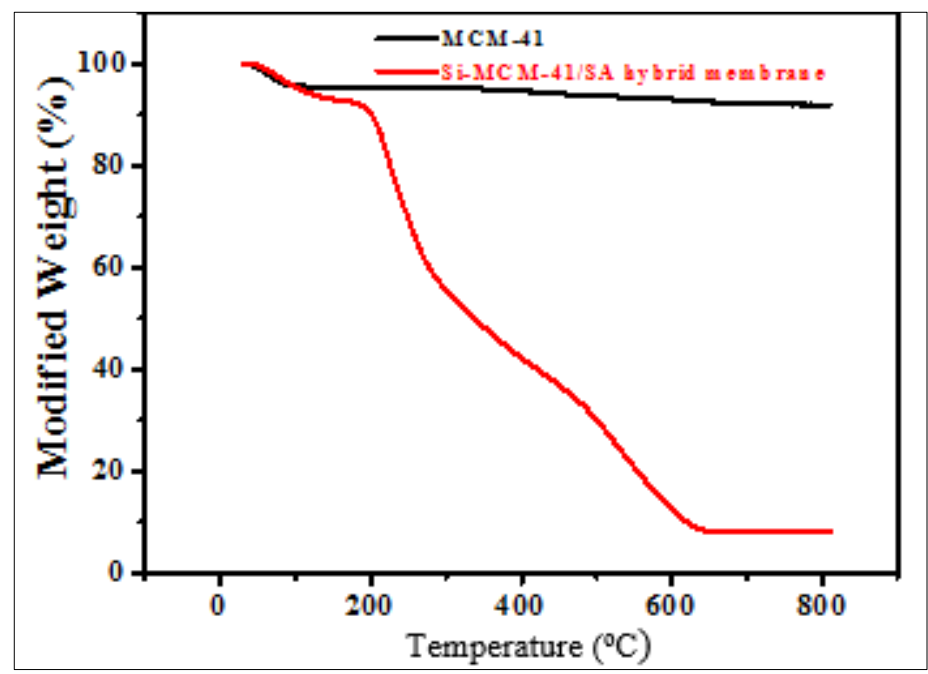

Figure 3. TG curve of hybrid membrane

\subsubsection{X-ray diffraction (XRD) analysis}

Figure 4 presented the XRD analysis of Si-MCM-41 and Si-MCM-41/SA porous hybrid membrane. From Figure 4, we can see that after adding of Si-MCM-41 onto SA matrix, it still has the characteristic peak of Si-MCM-41 [26], indicating that the skeleton structure of the Si-MCM-41 has not been destroyed.

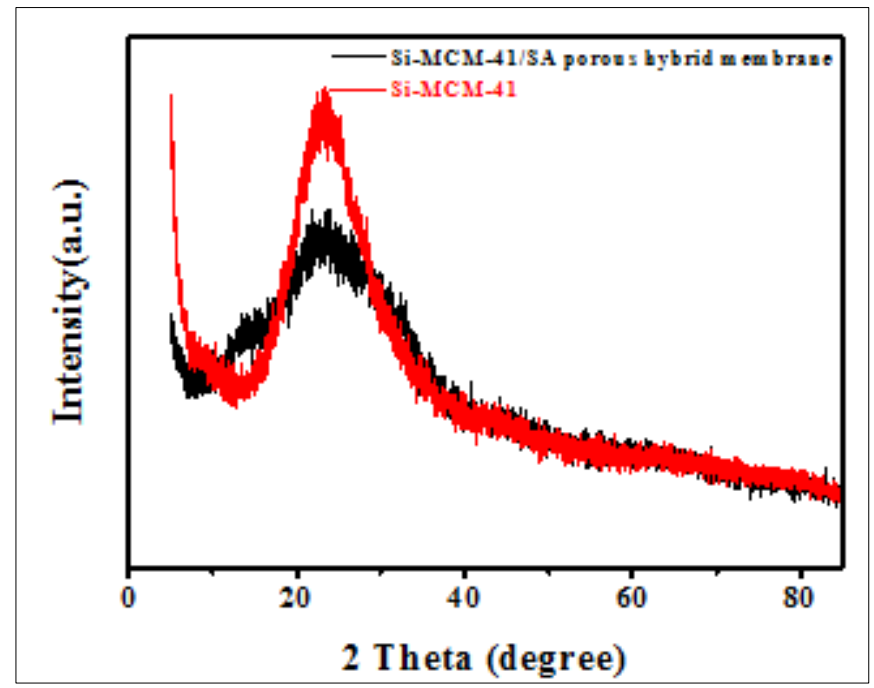

Figure 4. XRD pattern of Si-MCM-41 and hybrid membrane

\subsubsection{Atomic force microscope (AFM) analysis}

The roughness of SA pure membrane and Si-MCM-41/SA porous hybrid membrane are indicated in Figure 5. In the Figure 5a and b, we can know the surface roughness of SA pure membrane and Si- 
MCM-41/SA porous hybrid membrane are $56.7 \mathrm{~nm}$ and $65.4 \mathrm{~nm}$, respectively. With the addition of SiMCM-41, the roughness of the membrane increased, the specific surface area and the exposed active sites of the porous hybrid membrane also increased, which benefit for adsorption of p-DBT [27].

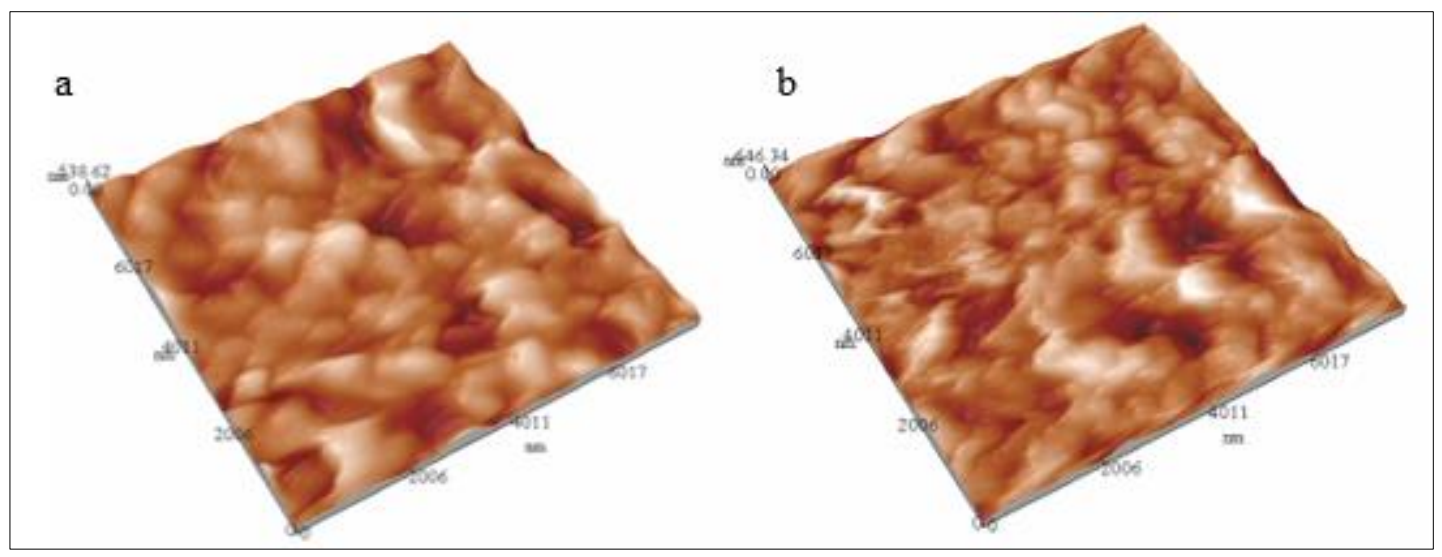

Figure 5. AFM images of a) SA pure membrane; b) Si-MCM-41/SA porous hybrid membrane

The nitrogen adsorption-desorption isotherms and pore size distribution of the adsorbents are indicated in Figure 6. Calculating by the method of BJH, Si-MCM-41 has a specific surface area of 1001 $\mathrm{m}^{2} \cdot \mathrm{g}^{-1}$ and an average pore diameter of $58 \AA$. According to the classification of adsorption-desorption curve, the figure conforms to the $\mathrm{S}$-shaped curve, which has the characteristics of mesoporous materials. In the second half of adsorption, multi-molecular layer adsorption and capillary condensation occurred, which belong to mesopores and micropores. It also can be seen that the material has abundant mesopores and a certain number of micropores. The molecular diameter of the prepared Si-MCM-41 molecular sieve is about $210 \mathrm{~nm}$, and the particle size is relatively uniform, which helps to obtain a hybrid film with uniform particle distribution and improve the adsorption effect.
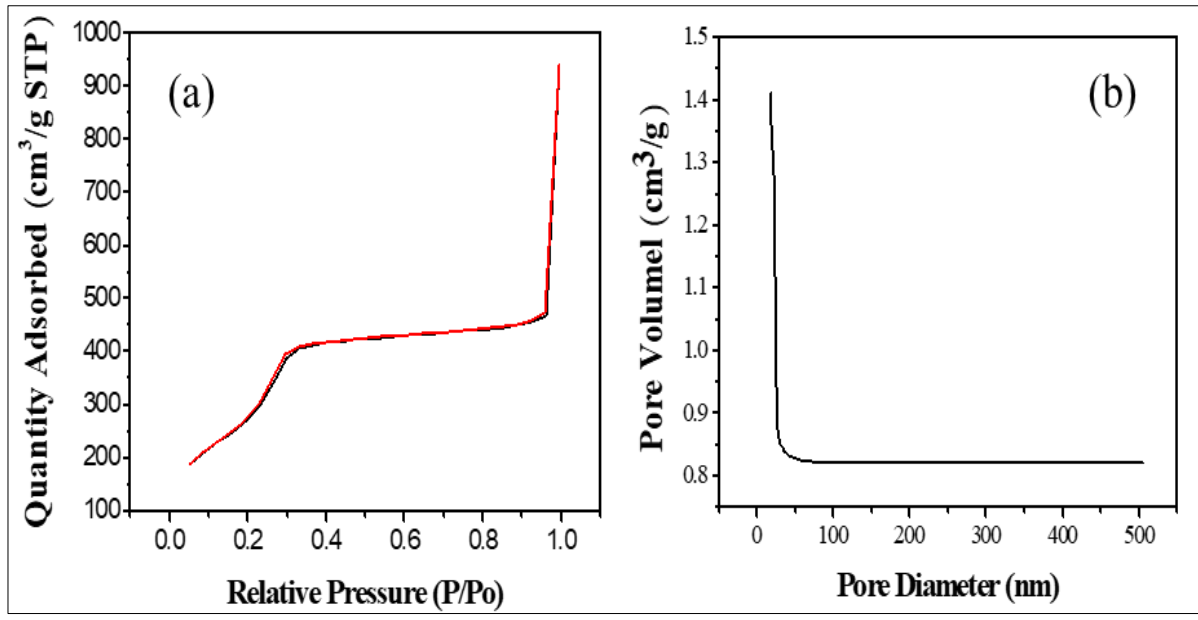

Figure 6. a) $\mathrm{N}_{2}$ adsorption-desorption isotherms;

b) pore size distribution of Si-MCM-41

\subsection{Data analysis}

\subsubsection{Effect of Si-MCM-41 content on adsorption property of Si-MCM-41/SA porous hybrid membrane}

The effect of Si-MCM-41 content on the adsorption of DBT on Si-MCM-41/SA porous hybrid membrane is demonstrated in Figure 7. As can be seen, the unit adsorption capacity of SA porous hybrid membrane first increases and then decreases with the increase of Si-MCM-41 content. When the content of Si-MCM-41 is $8 \mathrm{wt} \%$, the unit adsorption capacity of the Si-MCM-41/SA porous hybrid membrane 
is the highest. It may be that when the content of Si-MCM-41 is lower than $8 \mathrm{wt} \%$, the pore size of $\mathrm{Si}$ MCM-41 become the main factor affecting the adsorption effect [28-29]. With the increase of Si-MCM41 content, agglomeration began to occur, which reduce the number of active sites contacting with DBT and limite the increase of adsorption capacity.

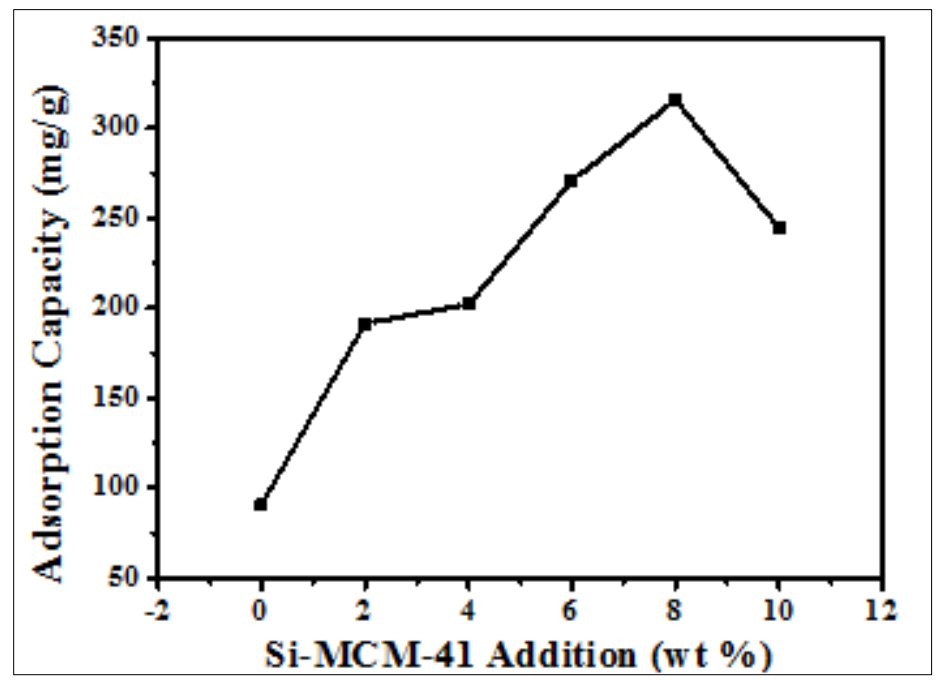

Figure 7. Effect of Si-MCM-41 addition on adsorption capacity

\subsubsection{Effect of porogen addition on adsorption property of Si-MCM-41/SA porous hybrid membrane}

Figure 8 shows the effect of porogen addition on the adsorption of DBT. It indicates that the unit adsorption capacity of SA porous hybrid membrane first increases and then decreases with the increase of content of polyvinylpyrrolidone (PVP). The main reason is that when the porogen dose is small, the pore distribution on the surface of the $\mathrm{Si}-\mathrm{MCM}-41 / \mathrm{SA}$ porous hybrid membrane is less, leading to the smaller specific surface area and less active site of Si-MCM-41/SA porous hybrid membrane exposed to the solution, which limits the adsorption effect. When the amount of porogen added is greater than 80 $\mathrm{wt} \%$, the specific surface area of the Si-MCM-41/SA porous hybrid membrane begins to decrease, which limits the adsorption effect of the Si-MCM-41/SA porous hybrid membrane. Therefore, when the content of PVP is $80 \mathrm{wt} \%$, the unit adsorption capacity of SA porous hybrid membrane is the highest and the adsorption effect is the best.

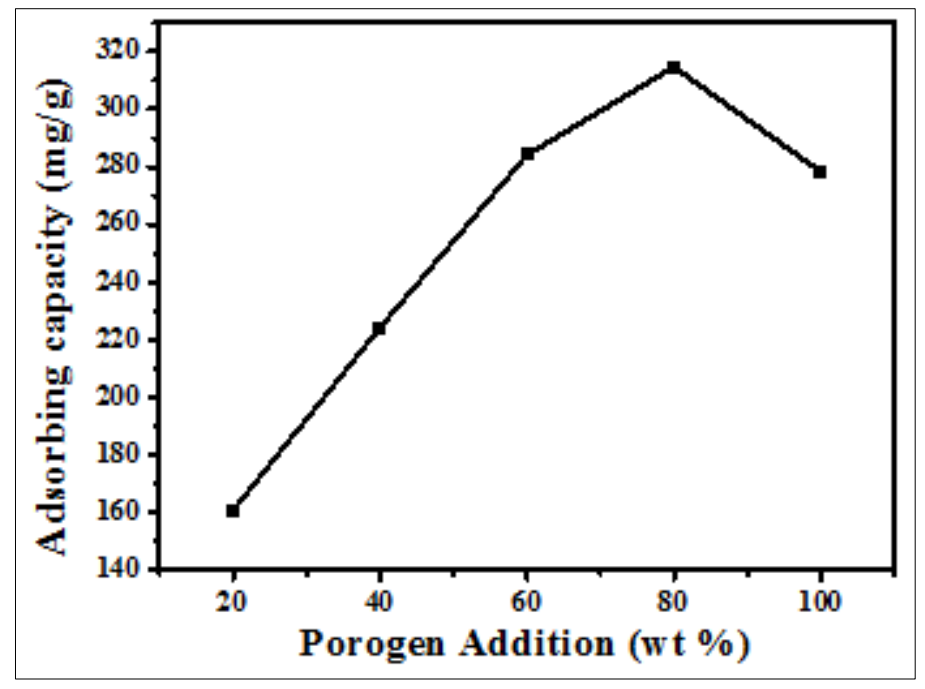

Figure 8. Effect of porogen addition on adsorption capacity 


\subsubsection{Adsorption kinetics}

It can be seen from Figure 9 that the adsorption capacity of Si-MCM-41/SA porous hybrid membrane rapidly rises in the first $120 \mathrm{~min}$, indicating that the adsorption rate was very fast in the early stage of the adsorption experiment. This mainly attributed to the strong coordination ability of hydroxyl, carbonyl and other groups on the surface of porous hybrid membrane with DBT. Meanwhile, the diffusion rate of DBT into the Si-MCM-41/SA porous hybrid membrane was faster because of the large concentration difference between the solution and the porous hybrid membrane. After 120 min, with the adsorption process, the concentration of DBT in the solution decreases, resulting in a lower concentration difference between the solution and the adsorbent. As a result, the diffusion driving force becomes smaller, thus the adsorption rate decreases. Finally, the adsorption gradually reaches saturation and reaches equilibrium state.

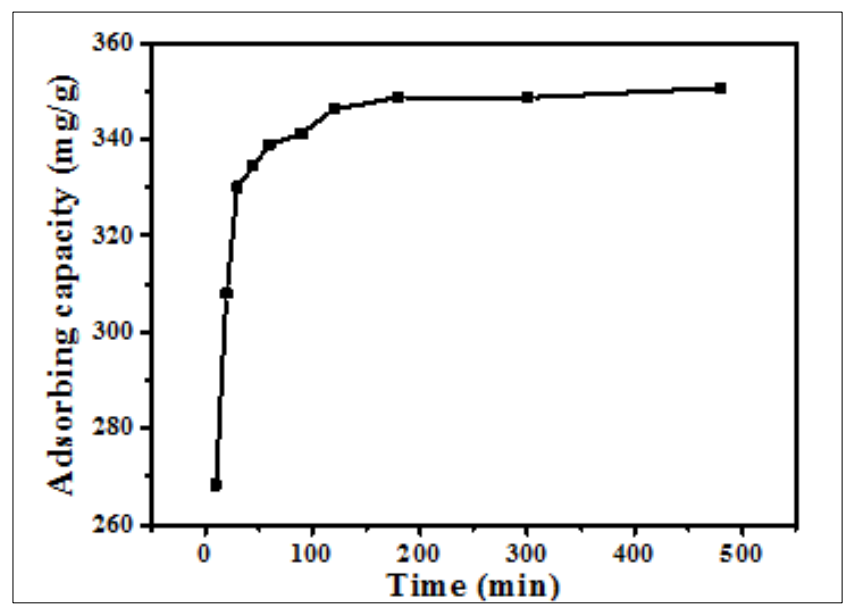

Figure 9. Effect of adsorption time on adsorption capacity

In order to explore the adsorption kinetics of DBT with Si-MCM-41/SA porous hybrid membranes, the pseudo-second-order kinetic model [30,31] was used to fit and analyze the adsorption kinetic data. The pseudo-second order kinetic equation is as follows [32]:

$$
\begin{aligned}
t / q_{t} & =1 / v_{o}+t / q_{e} \\
v_{o} & =k_{2} q_{e}{ }^{2}
\end{aligned}
$$

$q_{e}(\mathrm{mg} / \mathrm{g})$ is the adsorption capacity at equilibrium, $q_{t}(\mathrm{mg} / \mathrm{g})$ is the adsorption capacity at time $\mathrm{t}$, and $v_{o}$ $(\mathrm{mg} /(\mathrm{g} \cdot \mathrm{min}))$ represents the initial rate, $\mathrm{k}_{2}$ represents the rate constant of the quasi-second-order kinetic model.

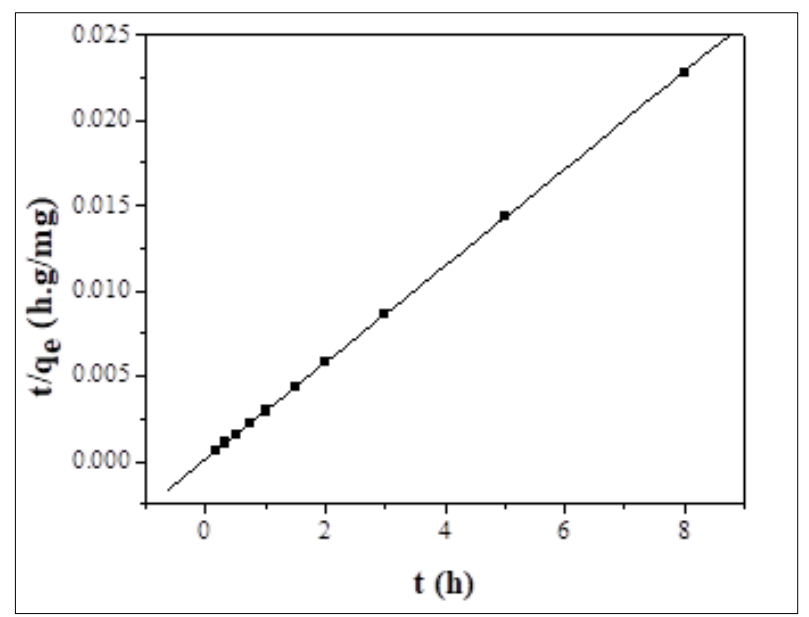

Figure 10. Curve of pseudo-second-order dynamics equation 
The pseudo-second-order kinetic results of the Si-MCM-41/SA porous hybrid membrane for DBT are shown in Figure 10. According to the pseudo-second-order kinetic equation and the slope and intercept of the pseudo-second-order kinetic line in the Figure 10 , we can get $\mathrm{q}_{\mathrm{e}}=350.74 \mathrm{mg} / \mathrm{g}, \mathrm{k}_{2}=$ $0.06774 \mathrm{~g} /(\mathrm{mg} \cdot \mathrm{h})$, and the correlation coefficient $\mathrm{R}^{2}=0.9999$, indicating that the adsorption kinetics of the Si-MCM-41/SA porous hybrid membrane for DBT satisfies the pseudo-second-order adsorption kinetics equation well. This indicates that the control step of Si-MCM-41/SA porous hybrid membrane for DBT is chemistry adsorption.

\subsubsection{Effect of DBT concentration on adsorption property of Si-MCM-41/SA porous hybrid membrane}

Figure 11 illustrates the effect of DBT concentration on the adsorption of DBT. It can be seen that as the concentration of DBT increases, the adsorption capacity shows an upward trend. It is because the adsorption-desorption process of the sulfide by the hybrid membrane is reversible [15]. Increasing the initial concentration of the sulfide is equivalent to increasing the adsorption driving force, moving the balance to the direction of adsorption, which causes the adsorption capacity increases with the increase of the sulfide concentration. Moreover, as the concentration of the solution increases, the concentration difference between the surface of the Si-MCM-41/SA porous hybrid membrane and the solution increases, this increases the contact probability between DBT and the active site in the Si-MCM-41/SA porous hybrid membrane, which helps increase the adsorption capacity.

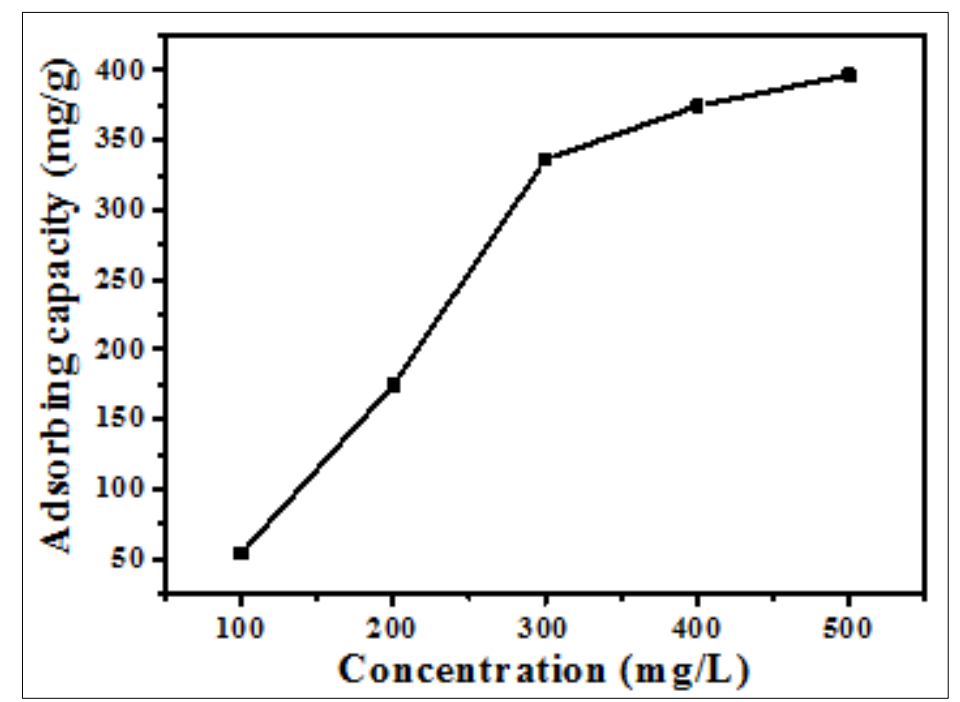

Figure 11. Effect of concentration on adsorption capacity

\subsubsection{Effect of temperature on adsorption property of Si-MCM-41/SA porous hybrid membrane}

From Figure 12 we can see that as the adsorption temperature increases, the adsorption amount shows a downward trend. As the adsorption temperature increases, the molecular chain movement rate of the sodium alginate-based membrane is increased, and the molecular movement speed of DBT becomes more intense, which weakens the coordination effect between the two [33]. When the temperature rises, the desorption rate is greater than the adsorption rate, so the adsorption capacity decreases. Therefore, it is necessary to control the appropriate adsorption temperature to make the porous hybrid membrane achieve the optimal adsorption state. 


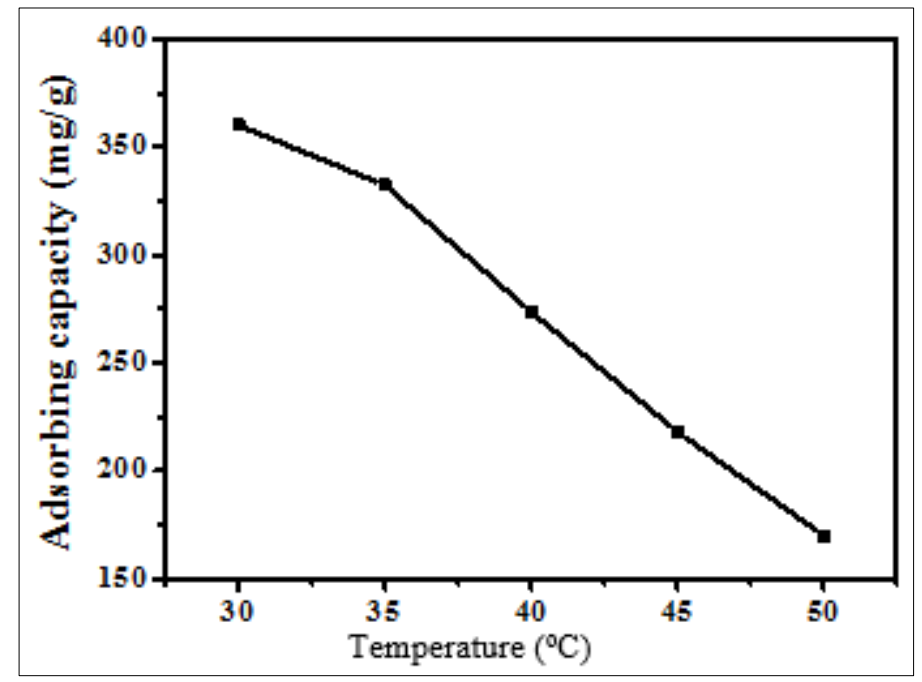

Figure 12. Effect of temperature on adsorption capacity

Based on the data obtained under different temperature conditions, the thermodynamic parameters of hybrid membrane adsorption of DBT, such as Gibbs free energy $\Delta \mathrm{G}_{0}$, enthalpy change $\Delta \mathrm{H}_{0}$ and entropy change $\Delta \mathrm{S}_{0}$, were discussed $[34,35]$. The calculation formula is as follows:

$$
\begin{gathered}
\ln \left(q_{e} / c_{e}\right)=-\Delta H / R T+\Delta S / R \\
\Delta G=\Delta H-T \Delta S
\end{gathered}
$$

where $\mathrm{R}(8.3145 \mathrm{~J} / \mathrm{mol} \cdot \mathrm{K})$ represents the ideal gas constant and $\mathrm{T}$ represents the absolute temperature in $\mathrm{K}$. The values of $\Delta \mathrm{H}$ and $\Delta \mathrm{S}$ can be calculated from the slope and intercept of the line obtained by plotting $\ln \left(\mathrm{q}_{\mathrm{e}} / \mathrm{c}_{\mathrm{e}}\right)$ against $1 / \mathrm{T}$ (Figure 13).

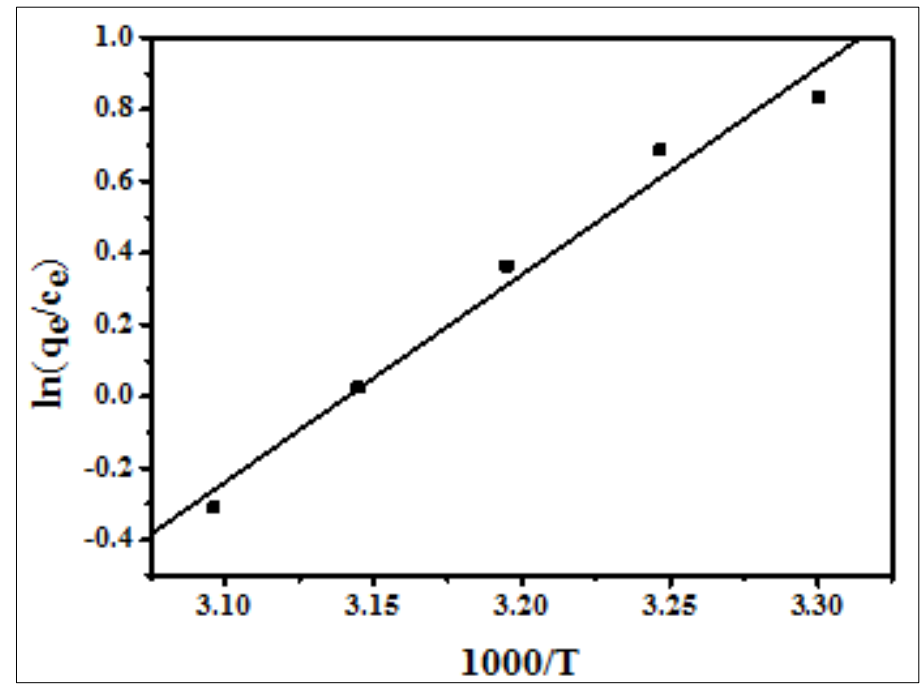

Figure 13. The relationship between $\ln \left(\mathrm{q}_{\mathrm{e}} / \mathrm{C}_{\mathrm{e}}\right)$ and $1000 / \mathrm{T}$

The calculation results are listed in Table 1. It can be seen from the table that when the temperature is less than $45^{\circ} \mathrm{C}, \Delta \mathrm{G}<0$, indicates that the positive reaction proceeds is spontaneous. $\Delta \mathrm{H}<0$, this indicates that the temperature decrease is conducive to the adsorption; $\Delta \mathrm{S}<0$, indicating that the adsorption process is a process of entropy decrease, and the degree of confusion at the solid-liquid interface during adsorption is reduced. Therefore, the follow-up experiment was conducted at room temperature. 
Table 1. Adsorption thermodynamic parameters at different temperatures

\begin{tabular}{|c|c|c|c|c|}
\hline \multicolumn{3}{|c|}{ Adsorbent $T / \mathrm{K}$} & $\Delta G(\mathrm{~kJ} / \mathrm{mol}) \Delta H(\mathrm{~kJ} / \mathrm{mol}) \Delta S(\mathrm{~J} / \mathrm{mol} \cdot \mathrm{k})$ \\
\hline Hybrid membrane & 303 & -2.31 & -48.04 & -150.91 \\
\hline & 308 & -1.56 & & \\
\hline & 313 & -0.80 & & \\
\hline & 318 & -0.05 & & \\
\hline & 323 & 0.70 & & \\
\hline
\end{tabular}

\subsubsection{Effect of toluene concentration}

The main components of gasoline are $\mathrm{C}_{4} \sim \mathrm{C}_{12}$ aliphatic hydrocarbons and cyclic hydrocarbons, and contain a small amount of aromatic hydrocarbons and sulfides [36]. Therefore, in order to further study the adsorption capacity of the hybrid membrane, we chose toluene to replace the aromatic hydrocarbons, and further study the adsorption effect of the hybrid membrane.

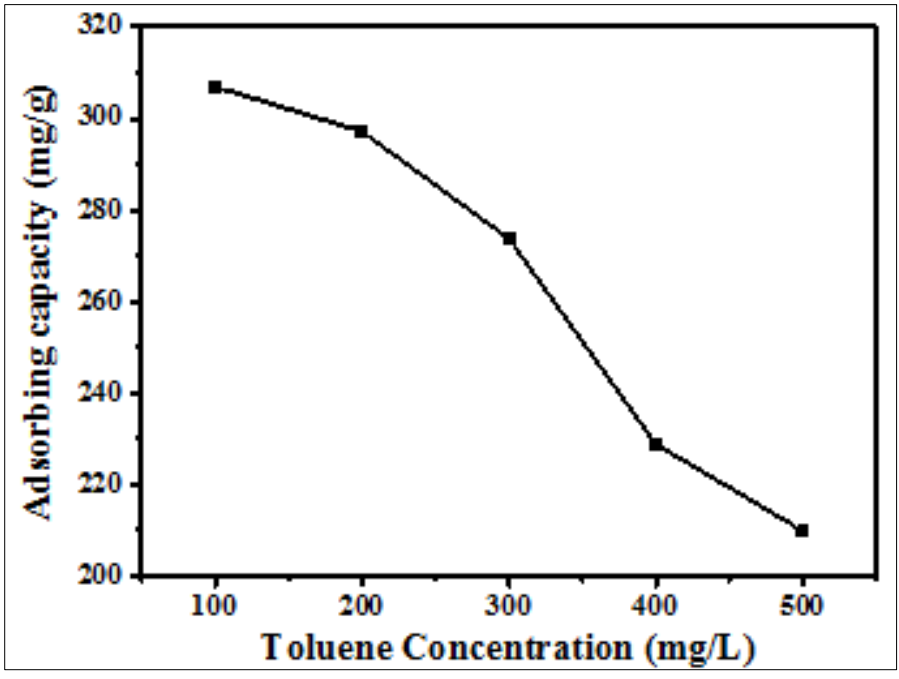

Figure 14. Effect of toluene concentration on adsorption capacity of hybrid membrane

The effect of toluene concentration on the adsorption of DBT is shown in Figure 14. Obviously, with the increase of toluene concentration, the adsorption capacity showed a downward trend, indicates that the presence of toluene has an inhibitory effect on the hybrid membrane adsorption of DBT, and toluene reduces the adsorption capacity of hybrid membrane for sulfide. Aromatic hydrocarbons in gasoline interact with metals through $\pi$ electrons, occupying adsorption sites, thereby generating a strong competitive effect on the adsorption of thiophene sulfides, which reduces the adsorption performance of adsorbents for sulfides. Thiophene sulfides can interact with Si through $\pi$ electrons, and the molecular structure of toluene also has $\pi$ electrons. Therefore, the $\pi$ electrons of toluene compete with thiophene sulfides and occupy part of the adsorption sites, which hinders the adsorption of thiophene sulfides [37]. Moreover, in terms of molecular size, toluene has a smaller molecular size than that of DBT, and toluene is easier to enter the interior of Si-MCM-41 molecules and adsorb. Therefore, the adsorption amount of DBT showed a downward trend with the increase of toluene concentration. 


\subsubsection{Selectivity}

As shown in Figure 15, the selectivity of the hybrid membrane was tested. we can see that under the same conditions, the amount of three solutes adsorbed shows an upward trend with an increasing of concentration. This is because the adsorption-desorption process is a reversible equilibrium process. Increasing the concentration will increase the driving force of adsorption and move the equilibrium to the direction of adsorption [38, 39]. At the same concentration, the amount adsorbed by the hybrid membrane is DBT > thiophene > 3-methylthiophene. According to Shujiro Otsuki et al. [40], when the electron cloud density of sulfur atoms is greater than 5.706, the reaction is easy to occur, and the reactivity increases with the increase of the electron cloud density. The electron cloud densities of sulfur in thiophene and DBT are 5.739 and 5.758, respectively, while the electron cloud densities of sulfur in 3-methylthiophene are between 5.696 and 5.706, which indicates that the adsorption reaction is easier carried out on thiophene and DBT. The adsorption strength of Si-MCM-41 and DBT is greater than that of thiophene, so the adsorption selectivity of hybrid membrane is DBT > thiophene > 3-methylthiophene.

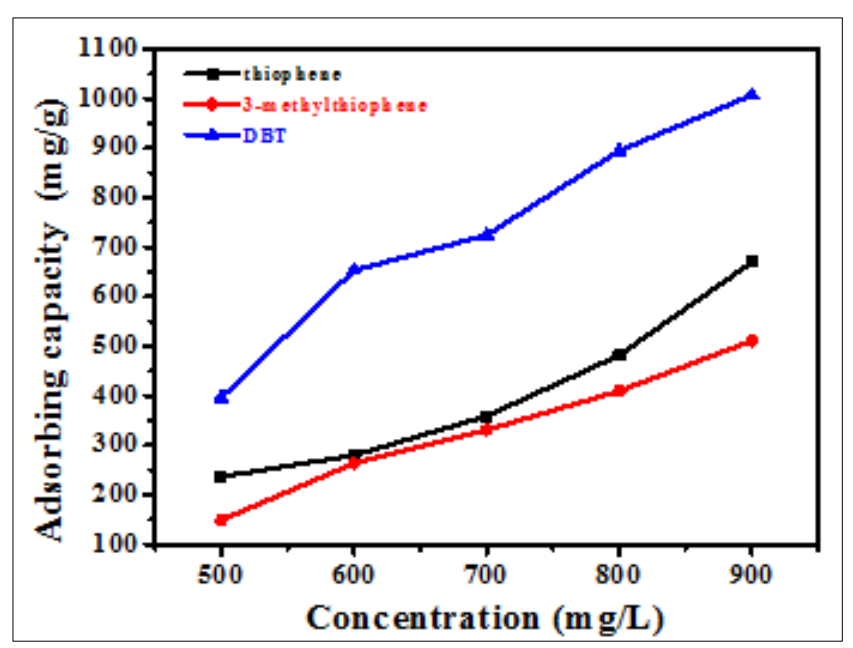

Figure 15. Concentration - adsorption relationship curve

\subsubsection{Repeatability}

In the actual use of the adsorbent, we must consider the economic costs. If the adsorbent can be reused and maintain a high-efficiency adsorption effect, in actual production, it will reduce the cost of the enterprise and reduce environmental pollution. Therefore, in order to verify the reusability of the hybrid membrane, we used static adsorption method [41,42]. After adsorption at a constant temperature of $30^{\circ} \mathrm{C}$ for $24 \mathrm{~h}$, the supernatant was taken to measure the amount of adsorption. The DBT was washed out from hybrid membrane by solvent elution [43], and the adsorption experiment is continued for 5 times.

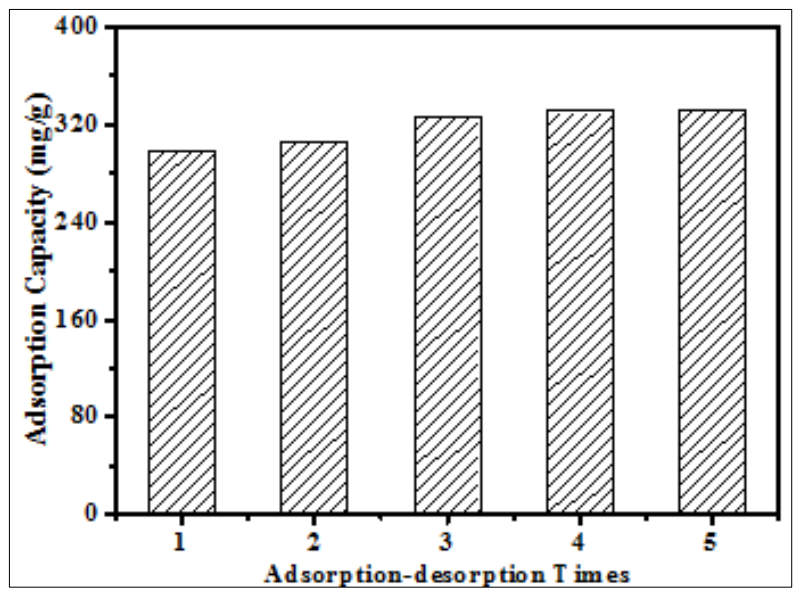

Figure 16. The relation curve of times and adsorption amount 
Figure 16 shows that Si-MCM-41 has a large adsorption capacity for DBT, and the curve rises first and then tends to be stable. The process of adsorption-desorption of sulfide by hybrid membrane is a reversible equilibrium process. The sulfur in DBT can combine with the Si-O bond in Si-MCM-41, and the adsorption effect is achieved due to the pore size effect of the Si-MCM-41 molecular sieve [44]. With the adsorption-desorption of the hybrid membrane, the pore size of the hybrid membrane becomes larger and the specific surface area increases, which increases the contact opportunities between DBT and the adsorbent, so that the adsorption amount is increased. Finally, the adsorption capacity of the hybrid membrane tends to be stable.

\section{Conclusions}

In this paper, the Si-MCM-41/SA porous hybrid membrane was prepared. By optimizing the amount of Si-MCM-41 and the porogen PVP, the Si-MCM-41/SA porous hybrid membrane with the best adsorption was obtained. The experiment results indicate that the adsorption capacity of Si-MCM-41/SA porous hybrid membrane for DBT were greatly affected by the Si-MCM-41 content, porogen addition, solution temperature, solution concentration, toluene concentration and adsorption time. The experimental results show that the $\mathrm{Si}-\mathrm{MCM}-41 /$ sodium alginate porous hybrid membrane shows a good adsorption effect on DBT, reaching $350.74 \mathrm{mg} / \mathrm{g}$, which is much higher than that of pure sodium alginate membrane. Among the DBT, thiophene and 3-methylthiophene, Si-MCM-41/SA porous hybrid membrane shows high selectivity for DBT. Regeneration experiments show that the Si-MCM-41/SA porous hybrid membrane own high reusability. In summary, it can be speculated that the prepared SiMCM-41/SA porous hybrid membrane is an ideal adsorption material with practical application prospects.

Acknowledgment:The authors would like to acknowledge the financial support of this work from National Natural Science Foundation of China (No. 21676133). The authors alsothank the anonymous referees for comments on this manuscript.

\section{References}

1.M. ZHENG, H., HU, Z., YE, Q. HUANG, X., Chen, J. Hazard. Mater. 2019, 362(15), 424-435.

2.T. ABBAS, M., MARZIEH, S., HOSSEIN, Int. J. Hydrogen Energ. 2018, 43(31), 14816-14833.

3.B. ZHANG, Z., JIANG, J. LI, Y. ZHANG, F., LIN, Y. LIU, C. LI, J. Catal. 2012, 287, 5-12.

4.X. WANG, P. CLARK, S. T. OYAMA, J. Catal. 2002, 208(2), 321-331.

5.M. HOUALLA, N. K. NAG, A. V. SAPRE, D. H. BRODERICK, B. C. GATES, Aiche J. 1978, 24(6), 1015-1021.

6.B. C. GATES, H., Topsøe, Polyhedron 1997, 16(18), 3213-3217.

7.L. ZHANG, Q. DAI, W. FU, T. TANG, P. DONG, M. HE, Q., Chen, J. Catal. 2018, 359, 130-142.

8.Y. ZHANG, Z. JIANG, J. SONG, J. SONG, F. PAN, P. ZHANG, X. CAO, Ind. Eng. Chem. Res. 2019, 58(36), 16911-16921.

9.K. X. LEE, J. A. VALLA, React. Chem. Eng. 2019, 4(8), 1357-1386.

10.Y. SHI, G. LIU, L. WANG, H. ZHANG, J. Colloid Interf. Sci. 2019, 557, 336-348.

11.L. ALVARADO-PEREA, J. A. COLÍN-LUNA, A. LÓPEZ-GAONA, T. WOLFF, J. G. PACHECOSOSA, J. C. GARCÍA-MARTÍNEZ, Catal. Today, 2019.

12.M. CHEN, Y. DING, Y. LIU, N. WANG, B. YANG, L. MA, Petrol. Sci. Technol. 2018, 36(2), 141147.

13.P. BRANDT, A. NUHNEN, M. LANGE, J. MÖLLMER, Acs Appl. Mater. Interfaces 2019, 11(19), $17350-17358$.

14.A. MUDHOO, A. BHATNAGAR, M. RANTALANKILA, V. SRIVASTAVA, M. SILLANPÄ̈̈, Chem. Eng. J. 2019, 360, 912-928.

15.Z. CHAO, C. LIU, P. DENG, H. HUANG, H. SUN, L. ZHANG, H. LIU, L. LIN, Y. ZHANG, New Chem. Mater. 2015, 43(08), 102-105. 
16.N. ZHANG, Z. PAN, L. ZHANG, Z. ZHANG, Fuel 2019, 242, 470-478.

17.J. A. S. COSTA, R. A. D. JESUS, D. O. SANTOS, J. F. MANO, L. P. C. ROMÃO, C. M. PARANHOS, Micropor. Mesopor. Mat. 2019, 291, 109698.

18.N. RAO, M. WANG, Z. SHANG, Y. HOU, G. FAN, J. LI, Energy Fuels 2018, 32(1), 670-677.

19.C. ClaUdiO, R. ElisabetTA, A. ANDREA, V. M. ANTONIO, C. CARLA, J. Nanosci. Nanotechno. 2019, 19(8), 5035-5042.

20.Y. GUAN, S. WANG, X. WANG, C. SUN, Y. WANG, L. HU, Micropor. Mesopor. Mat. 2018, 265, 266-274.

21.F. LIU, W. XIONG, X. FENG, L. SHI, D. CHEN, Y. ZHANG, J. Hazard. Mater. 2019, 367, 381389.

22.F. JU, T. WU, M. WANG, R. LIN, M. ZHAO, S. H. NG, H. LING, Ind. Eng. Chem. Res. 2019, 58(29), 13401-13407.

23.D. RUI, X. SUN, J. ZHANG, J. ZHOU, New Chem. Mater. 2014, 42(01), 65-66.

24.X. LI, M. TIAN, Y. CHENG, X. WANG, CHIN. J. Appl. Chem. 2019, 36(2), 203-211.

25.H. ZHANG, H. SUN, D. ZHANG, W. ZHANG, S. CHEN, M. LI, P. LIANG, Chem. Eng. J. 2019, 361, 139-147.

26.J. BAI, H. LI, H. ZHAO, J. Liaoning Shihua Univ. 2018, 38(1), 16-19.

27.T. WANG, X. ZHAO, Y. ZHANG, H. LI, Adv. Mater. Res. 2009, 79-82, 1935-1938.

28.D. M. MARZOUQA, M. B. ZUGHUL, M. O. TAHA, H. A. HODALI, J. Porous Mat. 2012, 19(5), 825-833.

29.W. ZHANG, R. ZHANG, Y. HUANG, J. YANG, Cryst. Growth Des. 2018, 18(12), 7533-7540.

30.E. M. MORALES-VALENCIA, C. O. CASTILLO-ARAIZA, S. A. GIRALDO, V. BALDOVINO, ACS Catal. 2018, 8(5), 3926-3942.

31.A. TANIMU, S. A. GANIYU, S. ADAMU, K. ALHOOSHANI, React. Chem. Eng. 2019, 4, 724737.

32.Q. ZHAI, Y. DONG, Instrum. Sci. Technol. 2019, 47(5), 467-484.

33.F. ZHOU, X. FENG, J. YU, X. JIANG, Environ. Sci. Pollut. Res. 2018, 25(16), 15651-15661.

34.M. RE FIORENTIN, R. GASPARI, M. QUAGLIO, G. MASSAGLIA, G. SARACCO, Phys. Rev. B 2018, 97(15), 155428.

35.C. DESGRANGES, J. DELHOMMELLE, American Chemical Society 2020; 37-72.

36.A. AITANI, M. N. AKHTAR, S. AL-KHATTAF, Y. JIN, O. KOSEOGLO, M. T. KLEIN, Energy Fuels 2019, 33(5), 3828-3843.

37.Z. LI, Y. JI, Y. ZHANG, X. ZHANG, X. LI, B. WU, X. LI, Chem. Ind. Eng. Prog. 2018, 37(10), 4053-4059.

38.A. GROSMAN, C. ORTEGA, Phys. Rev. B 2008, 78(8), 952-963.

39.J. ZHU, Y. LI, L. XU, Z. LIU, Ecotoxicol. Environ. Saf. 2018, 08(105), 115-125.

40.S. OTSUKI, T. NONAKA, N. TAKASHIMA, W. QIAN, A. ISHIHARA, T. IMAI, T. KABE, Energy Fuels 2000, 14(6), 1232-1239.

41.K. RAJCZYKOWSKI, K. LOSKA, Water, Air, Soil Poll. 2018, 229(1), 20.1-20.7.

42.M. L. MAIER, S. MILLES, S. SCHUHMANN, G. GUTHAUSEN, H. NIRSCHL, M. J. KRAUSE, Comput. Math. Appl. 2018, 76(11-12), 2744-2757.

43.N. M. LAFRENIÈRE, J. M. MUDRIK, A. H. C. NG, B. SEALE, N. SPOONER, A. R. WHEELER, Anal. Chem. 2015, 87(7), 3902-3910.

44.J. C. GARCÍA-MARTÍNEZ, H. A. GONZÁLEZ-URIBE, M. M. GONZÁLEZ-BRAMBILA, N. G. FLORES DEL RÍO, A. LÓPEZ-GAONA, L. ALVARADO-PEREA, J. A. COLÍN-LUNA, Top. Catal. 2018, 61(15-17), 1721-1733.

Manuscript received: 1.07 .2021 